\title{
SEGURIDAD, MIGRACIÓN Y COMERCIO EN LAS RELACIONES MÉXICO-ESTADOS UNIDOS DURANTE LA PRESIDENCIA DE DONALD TRUMP ${ }^{1}$
}

\author{
SECURITY, MIGRATION AND TRADE IN \\ MEXICO-UNITED STATES RELATIONS DURING THE \\ PRESIDENCY OF DONALD TRUMP
}

\section{LA SÉCURITÉ, LES MIGRATIONS ET LE COMMERCE DANS LES RELATIONS MEXIQUE-ÉTATS-UNIS SOUS LA PRÉSIDENCE DE DONALD TRUMP}

\author{
Reynaldo Yunuen Ortega Ortiz \\ El Colegio de México \\ yortega@colmex.mx
}

Resumen: El propósito de este artículo es analizar, a partir de la llegada de Donald Trump a la presidencia de Estados Unidos, los cambios en las relaciones entre México y Estados Unidos en tres áreas de política: la seguridad, la migración y el comercio. El artículo parte de una visión dahliana o relacional del poder en donde: "poder es la capacidad de A de hacer que B haga algo que de otra forma no haría".

Palabras clave: México; Estados Unidos; Trump; poder; Robert Dahl; política exterior; migración; seguridad; comercio.

Aвstract: The purpose of this article is to analyze, since the arrival of Donald Trump to the presidency of the United States, the changes in the relations

${ }^{1}$ Este artículo es resultado del proyecto: "Observatorio socio-político electoral Estados Unidos-México", financiado por el "Fondo de Apoyo Colmex a la Investigación" (FACI) de El Colegio de México. Agradezco la colaboración de Gabriela Cervantes y Luis Fernando Ramírez, becarios de investigación, quienes recabaron información bibliográfica y hemerográfica sobre migración y comercio entre México y Estados Unidos, la cual forma parte integral de este trabajo. Obviamente, los errores son responsabilidad del autor. 
between Mexico and the United States in three policy areas: security, migration and trade. The article is based on a concept of Dahlian or relational power where: "power is the ability of A to get B to do something he or she would otherwise not do."

Keywords: Mexico; United States; Trump; power; Robert Dahl; foreign policy; migration; security; trade.

\section{Traducción de Gonzalo Celorio Morayta}

Résumé: L'article examine les changements dans les rapports Mexique-ÉtatsUnis concernant la sécurité, les migrations et le commerce, depuis l'arrivée de Donald Trump à la présidence de son pays. Cette analyse est guidée par la vision de Dahl des rapports entre acteurs, selon laquelle le pouvoir est "la capacité de A d'obtenir que B fasse ce qu'elle n'aurait pas fait sans l'intervention de At".

Mots clefs: Mexique; États-Unis; Trump; pouvoir; Robert Dahl; politique étrangère; migrations; sécurité; commerce.

Traducción de Bernardo Mabire

Fecha de recepción: diciembre de 2018

Fecha de aceptación: febrero de 2019 
INTRODUGCIÓN. EL GONCEPTO DE PODER EN LAS RELAGIONES inTERNAGionales y LA ELEGCión DE DONALd TRUMP

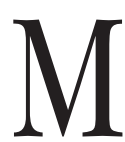
ÁS que un análisis de la política exterior, el texto busca, a partir de una visión dahliana o relacional del poder, en donde: "poder es la capacidad de A de hacer que B haga algo que de otra forma no haría",2 estudiar los cambios en las relaciones de poder entre Estados Unidos y México en tres áreas contingentes de política, a saber: la seguridad, la migración y el comercio.

Desde su campaña a la presidencia, Donald Trump insistió en la idea de que en sus relaciones internacionales, EEUU se encontraba en una situación desventajosa y que era tiempo de "Make America Great Again" (Hacer grandioso a EEUU otra vez). ${ }^{3}$ En junio de 2015, cuando lanza su campaña para la presidencia, Trump declara: "....ahora ellos (los mexicanos) nos están derrotando económicamente. No son nuestros amigos. Nos están matando económicamente. Estados Unidos se ha convertido en el tiradero de los problemas de los demás". ${ }^{4}$ La exageración del entonces candidato Trump era evidente, pero le sirvió para posicionarse como el candidato que defendía los intereses de su país.

Los resultados electorales fueron una sorpresa para la mayoría de los analistas y encuestadores que hasta el final insistían en que Hillary Clinton tenía la ventaja. Si bien ella obtuvo la mayoría del voto popular, 65853514 votos frente a 62984828 de Trump, él ganó la presidencia al obtener la mayoría de votos en el colegio electoral, con 304, ganando en 30 estados, frente a 227 votos del colegio electoral y 20 estados

${ }^{2}$ Robert Dahl, "The Concept of Power", Behavioral Science, 2, (julio de 1957), pp. 201-215.

${ }^{3}$ Carrie Grace, "Por qué la decisión de Trump de retirar a Eeuu del Acuerdo Transpacífico (TPP) es una gran noticia para China”, BBC News, 23 de enero de 2017, https://www.bbc.com/mundo/noticias-internacional-38063522

${ }^{4}$ Tuit de Donald Trump del 15 de junio de 2015, citado por Katie Railly, Time, 31 de agosto de 2016. 
que ganó Clinton. ${ }^{5}$ Mientras la candidata enfatizó en la campaña temas como los derechos de las minorías y las mujeres, la salud pública y lo que llamó "capitalismo incluyente", su oponente se centró en el lema "Hacer grandioso a Estados Unidos otra vez" pero, además, una y otra vez se dedicó a hablar negativamente de los migrantes mexicanos y sobre la necesidad de construir un muro en la frontera con México.

Un elemento internacional importante durante su campaña fue la intervención de Rusia; de acuerdo con el informe oficial de las agencias de inteligencia de Estados Unidos, el presidente de aquella nación, Vladimir Putin, consideró que Trump era una mejor opción para los intereses de su país y organizó una campaña para apoyarlo. En el mismo informe se argumenta que la intervención de Rusia en la campaña fue más allá de espiar los teléfonos de los asesores de la campaña demócrata, e incluyó la diseminación de mensajes y noticias falsas en las redes sociales; no simplemente se enviaron mensajes con información falsa, sino que a partir de los perfiles de los votantes se seleccionaron potenciales electores en distritos clave. Además, miembros de la campaña de Trump se reunieron con agentes rusos. ${ }^{6}$

Con una visión muy primitiva del poder, como si fuera un objeto que se posee, Trump considera, y así lo ha planteado ante sus electores hasta el cansancio, que Estados Unidos ha sufrido una serie de abusos en su contra e, incluso, que sus aliados tradicionales, los países europeos, Canadá y México, han abusado de la superpotencia y, por tanto, los acuerdos con estos países deben revisarse.

${ }^{5}$ Election Results for the U.S. President, the U.S. Senate and the U.S. House of Representatives, Federal Elections Commission, Washington D.C., diciembre de 2017, p. 5.

${ }^{6} \mathrm{Al}$ momento de terminar este artículo, está en curso una investigación dirigida por Robert Mueller (exdirector del FBI) sobre la intervención de gobiernos extranjeros en la campaña presidencial de 2016. La pesquisa se ha centrado en saber si hubo colusión entre la campaña del presidente Trump y los agentes rusos y, en su caso, si Trump ha obstruido la justicia de alguna manera. 
Considero que estudiar las tres áreas mencionadas nos permitirá ver los alcances de los esfuerzos del presidente estadounidense y la capacidad del actor débil, México, para resistir o modificar de alguna forma la situación.

El texto consta de cinco partes, incluyendo la introducción; en las secciones II, III y IV analizaré las tres áreas temáticas y, por último, plantearé algunas consideraciones finales.

Partiendo del concepto de poder desarrollado por Robert Dahl, las relaciones entre dos actores pueden analizarse a partir de los intereses de los mismos, en este caso, EEUU y México. Como sostiene Baldwin, en una relación dual existen nueve posibles escenarios en las relaciones de influencia.

\section{Cuadro 1}

Escenario de poder en una relación dual

\begin{tabular}{ccc}
\hline Escenario & Actor A (EEUU) & Actor B (México) \\
\hline 1 & Gana & Gana \\
2 & Gana & Pierde \\
3 & Pierde & Gana \\
4 & Empata & Empata \\
5 & Gana & Empata \\
6 & Pierde & Empata \\
7 & Empata & Gana \\
8 & Empata & Pierde \\
9 & Pierde & Pierde \\
\hline
\end{tabular}

Fuente: David Baldwin, Power and International Relations. A conceptual Approach, Princeton, University Press, 2016, p. 62.

El propósito del resto del artículo buscará conocer, ¿qué tipo de escenario ha prevalecido en las relaciones entre Estados Unidos y México en cada una de las áreas temáticas y cómo es que la presidencia de Donald Trump ha afectado ese escenario? 


\section{Las RElaciones México-Estados Unidos} Y EL TEMA DE LA SEGURIDAD

Como argumenta Baldwin, no fue sino hasta finales de los años treinta, sobre todo después de la Segunda Guerra Mundial, que la visión de la llamada escuela realista de relaciones internacionales cobró auge hasta convertirse en una visión dominante, por lo menos hasta finales de los años setenta. Es verdad que dentro del realismo se han desarrollado múltiples corrientes: "realismo clásico, realismo neoclásico, realismo estructural/neorrealismo, realismo de la naturaleza humana, realismo defensivo y realismo ofensivo, por sólo mencionar algunos"7 y hay importantes discusiones entre ellas, pero para todas, la seguridad de los Estados es prioritaria debido a la naturaleza "anárquica" del sistema internacional. Ahora bien, como lo estudió Lorenzo Meyer, las relaciones entre México y Estados Unidos a lo largo de casi 200 años de vida independiente de México han pasado por todo tipo de conflictos, incluyendo las dos guerras del siglo xIX y las múltiples intervenciones militares estadounidenses en territorio mexicano en los siglos XIX y Xx. ${ }^{8}$

En términos de costos, sin duda, para México la relación con este país ha tenido un precio muy alto; primero perdimos Texas en 1836 y luego, con la guerra de 1846-1848, más de la mitad del territorio. Está claro que para nuestro país todo el siglo xix en el área de seguridad fue una relación tipo 2 en los escenarios dahlianos, es decir, A (EEUU) ganó y B (México) perdió.

Con la restauración de la República en 1867, pero sobre todo con la dictadura de Porfirio Díaz (1877-1910), el Esta-

${ }^{7}$ R. Harrison, Wagner, War and the State: The Theory of International Politics, Ann Arbor, MI: University of Michigan Press, 2007, p. 12. Citado por D. Baldwin, en: Power and International Relations. A conceptual Approach, Princeton, Princeton University Press, 2016, p. 125.

${ }^{8}$ Lorenzo Meyer, "The United States and Mexico, The Historical Structure Of Their Conflict", en Journal Of International Affairs, vol. 43 núm. 2 (invierno de 1990), pp. 251-271. 
do mexicano logró finalmente un control mínimo de su territorio; sin embargo, la Revolución sería otra oportunidad para Estados Unidos y en general para las "grandes potencias europeas" de intervenir en la política mexicana. Los libros de Berta Ulloa, Friedrich Katz y Lorenzo Meyer ${ }^{9}$ sobre la época, muestran los múltiples esfuerzos de las potencias para influir en México. Sin duda el caso más grave fue el golpe de Estado contra Francisco I. Madero organizado en la misma embajada de Estados Unidos, el cual destruyó a la joven democracia y reafirmó a los revolucionarios en su convicción de mantener a la potencia lo más alejada posible de la política interior mexicana.

El presidente Woodrow Wilson buscó "corregir" lo que el embajador Wilson había ayudado a destruir, ocupando el puerto de Veracruz. Esta vez los revolucionarios mexicanos, y en particular Venustiano Carranza, ejercerían lo que en la literatura sobre el poder se ha llamado el "poder de los débiles" y con múltiples tácticas de resistencia insistió en la necesidad de que Eeuu dejara que México terminara su revolución. Sin duda, el cambio en la estructura internacional a raíz de la Primera Guerra Mundial y la necesidad del vecino del norte de no tener un frente abierto en el sur, fueron factores que permitieron a México la posibilidad de consolidar su nueva constitución. Curiosamente, en un momento de enorme debilidad del Estado mexicano (de hecho, las fuerzas constitucionalistas ni siquiera controlaban todo el territorio nacional), el país logró pasar del escenario 2 al escenario 7, en donde A (EEUU) empata y B (México) gana.

La formación y fortalecimiento del régimen autoritario en México entre 1928 y 1934 no puede explicarse sin el acuerdo entre Plutarco Elías Calles y el embajador Dwight Morrow,

${ }^{9}$ Berta Ulloa, La revolución intervenida: relaciones diplomáticas entre México y Estados Unidos (1910-1914), México, El Colegio de México, 1971. Friedrich Katz, La guerra secreta en México: Europa, Estados Unidos y la Revolución Mexicana, México, Era, 1982. Lorenzo Meyer, Su majestad británica contra la Revolución mexicana, 1900-1950: el fin de un imperio informal, México, El Colegio de México, 1991. 
quien estableció las "reglas del juego" entre los dos países, por lo menos hasta la nueva confrontación con México en 1938 a raíz de la expropiación petrolera. Durante casi una década el escenario fue del tipo 1, una relación de ganar, ganar. Estados Unidos salió de la Primera Guerra Mundial fortalecido y los revolucionarios mexicanos iniciaron la "institucionalización” de su régimen. El cardenismo y, en particular, la expropiación petrolera, ha sido uno de los breves momentos en las relaciones entre EEuU y México donde A pierde y B gana (escenario tipo 3). El triunfo de B se explica tanto por la consolidación de un Estado posrevolucionario, como por los cambios en el sistema internacional. La entrada del vecino del norte a la Segunda Guerra Mundial en 1941 le permitiría a México consolidar la expropiación petrolera y, a la vez, convertirse en su aliado. Con el fin de la guerra y el establecimiento de un nuevo orden internacional bipolar, las relaciones en materia de seguridad entre ambos países pueden considerarse del tipo 1, en donde tanto A como B ganaron. Aunque distante y con algunas mínimas resistencias, México siempre actuó cooperando con EEuU. La famosa tesis Ojeda, según la cual "Estados Unidos reconoce y acepta la necesidad de México de disentir de la política norteamericana en todo aquello que le resulte fundamental a México, aunque para los Estados Unidos sea importante, mas no fundamental. A cambio de ello México brinda su cooperación en todo aquello que, siendo fundamental o aun importante para Estados Unidos, no lo es para el país", ${ }^{10}$ mostraba la estabilidad en la relación.

Ahora bien, eso empezó a cambiar al final de los años sesenta, cuando la estabilidad del régimen autoritario mexicano y nuevos problemas se empezaron a vislumbrar en el horizonte; éstos tuvieron que ver con el espinoso y complicado tema del narcotráfico, que se ha convertido en una crisis humanitaria para México.

${ }^{10}$ Mario Ojeda, Alcances y límites de la política exterior de México, México, El Colegio de México, 1976, p. 93. 
El régimen de prohibición de las drogas tiene sus orígenes a principios de siglo xx, con la ley de 1909, y luego en 1914, con la Ley Harrison, ${ }^{11}$ que prohibió todos los usos no medicinales del opio, la morfina, la cocaína y, en 1937, con la ley sobre el impuesto a la marihuana, que ilegalizó su consumo. Así, desde principios del siglo xx, Estados Unidos enmarcó el combate al narcotráfico como una política de seguridad, y los gobiernos mexicanos han aceptado, desde mi punto de vista equivocadamente, esa visión.

Durante un breve periodo en 1938, México intentó una política totalmente distinta encabezada por Leopoldo Salazar Viniegra, quien argumentó que se podría controlar el tráfico de drogas de tres maneras: al crear un sistema estatal de distribución de drogas; al implementar una campaña de salud pública para educar a la gente en el consumo y consecuencias de las drogas, y al establecer un sistema de clínicas para el tratamiento de las adicciones. ${ }^{12}$

La política estadounidense creó el mercado ilegal de exportación de drogas desde México a Estados Unidos. El estudio de Salazar Viniegra, "El mito de la marihuana", ${ }^{13}$ concluía que el uso de ésta no provocaba psicosis o comportamientos criminales violentos y sostenía que fumarla creaba menos problemas sociales que el alcohol. Sin embargo, en Estados Unidos la política del comisionado federal contra los narcóticos, Harry Anslinger (quien dirigió la lucha contra las drogas entre 1930 y 1962), insistió en que los adictos primero eran criminales y después adictos. ${ }^{14}$

11 Para un análisis de los orígenes de la Ley Harrison, véase Steven R. Belenko (ed.), Drugs and Drug Policy in America: A Documentary History, Westport, Connecticut, Greenwood Press, pp. 47-65.

12 William Walker, Drug Control in the Americas, Albuquerque, University of New Mexico Press, 1981, pp. 124-125.

13 Salazar Viniegra, Leopoldo, "El mito de la marijuana", Criminalia, México, diciembre de 1938, pp. 206-37.

${ }^{14}$ Para un análisis histórico sobre este periodo, véase Froylán Enciso, Nuestra historia narcótica: pasajes para (re)legalizar las drogas en México, México, Debate, 2015. 
Anslinger y el Departamento de Estado no tolerarían la política mexicana de legalizar y regular el mercado de las drogas, con lo que impusieron un embargo a todas las medicinas de Eeuu a México. El secretario de Salud, José Siurob, trató de convencer a los estadounidenses de las ventajas del programa de salud mexicano, pero fracasó y tuvo que cancelarse. Nuevamente, en este caso, desde la perspectiva estadounidense el escenario fue del tipo 2, A gana y B pierde, aunque en realidad fue del tipo 9 , en donde los dos actores perdieron.

Entre los años sesenta y ochenta, EEUU realizó diversas operaciones en México con el fin de combatir el narcotráfico. En 1969, el presidente Nixon lanzó la Operación Intercepción y, a principios de los ochenta, Ronald Reagan la Operación Cóndor, que buscaban erradicar los plantíos en el famoso "triángulo dorado". La consecuencia de estas operaciones, además de la devastación ecológica en los estados mexicanos, fue el aumento del precio de la droga y la búsqueda de los narcotraficantes de nuevos lugares para cultivar; los cárteles pasaron de Durango y Sinaloa a Michoacán, Guerrero y Chiapas. Además, los cárteles mexicanos se empezaron a especializar en el trasiego de cocaína colombiana hacia EEUU.

Con la firma del TLCAN, el aumento de los flujos comerciales hacia Estados Unidos y el incremento de la demanda de drogas en ese país creció, así como la capacidad de los cárteles mexicanos para satisfacer esa demanda y multiplicarse y, dada la facilidad de adquirir armas de alto calibre en Estados Unidos, estas organizaciones criminales se armaron con gran facilidad, creando una situación de inseguridad y violencia creciente en México.

Si bien la violencia de los cárteles mexicanos fue en aumento desde las administraciones de los presidentes Ernesto Zedillo y Vicente Fox, fue con el inicio de la "guerra contra las drogas" de Felipe Calderón que la violencia llegó a niveles no vistos en México desde hacía más de medio siglo.

Entre 2006 y 2015, Calderón envió más de 50000 soldados y 5000 policías federales a las calles de las ciudades y pueblos 
de México. Como puede apreciarse en la siguiente gráfica, el resultado fue un aumento drástico en el número de homicidios en el país, al pasar de 10452 en 2006 a 25967 en 2012. Estados Unidos apoyó la "guerra de Calderón" contra las drogas con la Iniciativa Mérida, que consistió en un paquete de ayuda de 1.9 mil millones de dólares que se destinarían a la compra de helicópteros, aviones, así como una serie de programas de apoyo técnico para la marina y el ejército mexicanos. Según algunos analistas, la "guerra contra las drogas" ha tenido una función dual en el mundo; por una parte, están las ganancias de un mercado controlado por organizaciones criminales trasnacionales y, por otra, se ha formado un complejo militar industrial integrado por las agencias encargadas de combatir el tráfico de drogas en Estados Unidos y en México. Las operaciones de la DEA en nuestro país han causado múltiples fricciones entre ambas naciones y han llevado a una militarización creciente de la frontera.

En términos financieros, los bancos administran e invierten entre 350 y 500000 millones de dólares al año como parte de las ganancias de las organizaciones criminales en el mundo. Las redes de lavado de dinero incluyen abogados, intermediarios y administradores de fondos de inversión que utilizan 150000 millones de dólares anualmente. Según el Centro Nacional de Inteligencia sobre las Drogas, se estima que las organizaciones criminales mexicanas y colombianas, generan y lavan entre 18 y 39000 millones de dólares anualmente. ${ }^{15}$

$\mathrm{Al}$ inicio del sexenio de Enrique Peña Nieto se buscó reducir el énfasis en el combate al narcotráfico y, si bien de manera limitada, en 2014 parecía que disminuía la violencia, reflejada en el número de homicidios que se redujo a 20 010; no obstante, entre 2015 y 2017 la cifra volvió a incrementarse hasta llegar a más de 32000 homicidios.

15 National Drug Threat Assessment, National Drug Intelligence Center, U.S. Department of Justice, 2009, https:/ / www.justice.gov/archive/ndic/ pubs31/31 379/31379p.pdf 
GRÁFICA 1

Homicidios por cada 100000 habitantes, 2006-2017

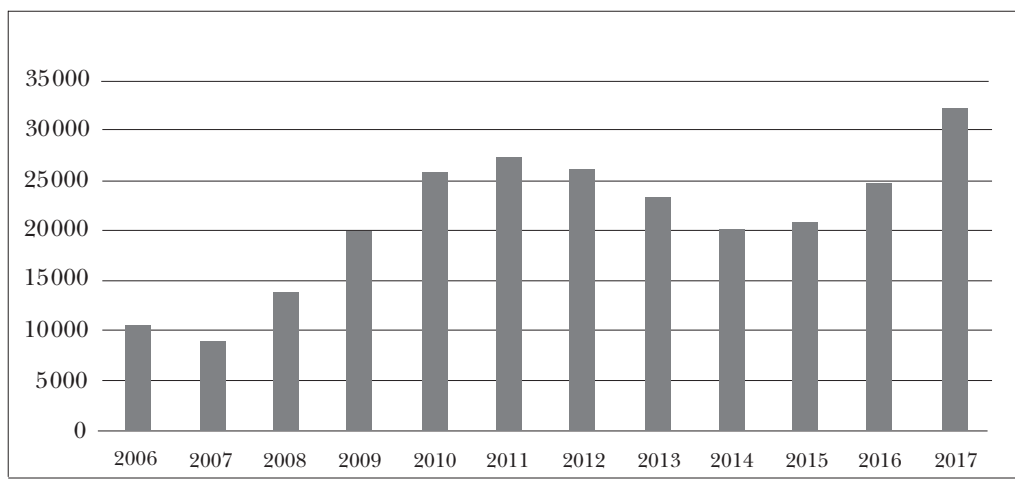

Fuente: INEGI, www.inegi.org.mx

Diversos informes de Human Rights Watch y de la misma CNDH en México muestran el aumento de los asesinatos, tortura y todo tipo de abusos a los derechos humanos; el caso de los 43 estudiantes desaparecidos de Ayotzinapa es el más conocido.

En términos de la relación binacional, el marco de referencia sigue siendo la Iniciativa Mérida, la cual retoma la idea del narcotráfico como un problema de seguridad nacional. Me parece que en la relación entre México y EeuU, ese encuadre ha llevado a México a ser siempre el actor perdedor.

México ha insistido que la responsabilidad es compartida y que la causa última del problema es la demanda, no sólo la oferta de las drogas, sin embargo, hasta ahora, la visión del gobierno mexicano ha seguido la pauta dictada por Estados Unidos, militarizando el tema.

Donald Trump argumentó en su campaña presidencial que el establecimiento de un muro en la frontera sería parte de la solución al problema. Es evidente que un muro fronterizo no tendrá efecto significativo en los canales de distribución de la droga, que no sólo se traslada por tierra, sino también por mar y por aire. Los recursos deberían invertirse en pro- 
gramas de salud para atender a la población con problemas de adicciones y en un mayor control del tráfico de armas. En la comunidad de negocios, que conoce bien el presidente Trump, el consumo de cocaína, heroína y todo tipo de drogas sintéticas "recreativas" está en aumento, sin que hasta el momento su administración tenga ninguna propuesta mínima al respecto; no hemos visto a agentes estadounidenses entrar a las fiestas de grandes corporativos para incautar las drogas. Desde el fracaso de la política prohibicionista de la década de los años veinte y el más reciente revés en la guerra contra las drogas de la administración del presidente Ronald Reagan, quedó claro que esa política no tiene sentido. La legalización de la marihuana en Colorado y Washington muestra una política completamente distinta a nivel estatal. En México, el nuevo gobierno de Morena ha propuesto una ley federal para la legalización de la marihuana. Ahora bien, ésta no tiene por qué llevar a que México deje de combatir el crimen organizado. Lo que se buscaría es intensificar los esfuerzos del gobierno en el control del lavado de dinero y los crímenes vinculados como la trata de personas, la extorsión y el secuestro, entre otros. Es necesario combatir también la infiltración de los criminales en los cuerpos policiacos y evitar el control de gobiernos municipales de grupos de narcotraficantes; además, el Estado mexicano debería tener una política amplia y bien financiada de salud pública sobre adicciones.

Es probable que EeuU no acepte con facilidad una "nueva” política mexicana, razón por la cual nuestro país tendría que, como lo hizo el vecino país con el TLGAN, dar por terminada la Iniciativa Mérida y buscar un nuevo entendimiento. Otra opción es la que se siguió en el área de migración una vez que terminó el acuerdo de braceros: no tener una política explícita. México sí puede disminuir unilateralmente la militarización del combate al narcotráfico y enmarcar el problema en el ámbito de la salud pública. Los costos muy probablemente serán grandes, pero difícilmente mayores a los más de 150000 muertos que hemos tenido en los últimos años con la política de militarización. 
En su más reciente informe, "Evaluación sobre las amenazas del narcotráfico”, la DEA considera que seis cárteles mexicanos: Sinaloa, Jalisco Nueva Generación, el cártel de Juárez, el cártel del Golfo, los Beltrán Leyva y Los Zetas, y en particular los dos primeros, "siguen siendo la principal amenaza narcotraficante criminal para Estados Unidos”. En el documento queda claro que estas organizaciones, en alianza con grupos criminales de Estados Unidos, han tenido la capacidad para expandir sus operaciones. Según el mismo informe, las drogas se distribuyen en las principales ciudades norteamericanas. El crecimiento de la demanda muestra una política pasiva de Estados Unidos en su territorio. Sin duda serían necesarias cooperación y corresponsabilidad para enfrentar la situación pero, hasta el momento, la administración de Trump no ha cambiado la política de su nación.

Las administraciones de Clinton, Bush y Obama buscaron crear un régimen de seguridad centrado en los intereses comunes de Estados Unidos, Canadá y México; sin embargo, con su retórica, el presidente Trump presenta a su electorado una visión aislacionista incapaz de hacer frente a las realidades de la seguridad hemisférica actual. Las consecuencias no buscadas de la política militarista del presidente conllevan una mayor desconfianza y menor cooperación. En este caso, el escenario de la relación es del tipo 9, México pierde, aunque Estados Unidos también pierde. Analicemos ahora la situación en la política de migración.

\section{LA MIGRACIÓN}

El otro tema que enfatizó Trump en su campaña fue el de la migración indocumentada a EEUU. Ésta ha sido una cuestión conflictiva en las relaciones entre México y Estados Unidos desde hace décadas y las últimas administraciones norteamericanas han enfatizado la necesidad de controlar los flujos migratorios y, en su caso, deportar a los migrantes indocumentados. 
Como podemos constatar en el cuadro 3, el mayor número de detenciones y deportaciones de mexicanos en Estados Unidos tuvo lugar durante la administración del presidente Obama, cuando más de 400000 mexicanos fueron detenidos y más de 240000 fueron deportados. Durante el primer año de la administración del presidente Trump, se deportó a más de 128000 mexicanos. Esta situación se explica porque los flujos migratorios se han modificado y la migración indocumentada de mexicanos hacia Estados Unidos ha disminuido, al menos desde la crisis económica de 2008.

\section{CuAdro 2}

Aprehensiones y deportaciones de inmigrantes mexicanos sin documentos en Estados Unidos y connacionales repatriados a México entre 2012 y 2016

\begin{tabular}{cccc}
\hline Anual & $\begin{array}{c}\text { Aprehensiones de } \\
\text { inmigrantes mexicanos } \\
(\text { en EEUU)* }\end{array}$ & $\begin{array}{c}\text { Deportaciones de } \\
\text { mexicanos } \\
(\text { desde EEUU)** }\end{array}$ & $\begin{array}{c}\text { Repatriaciones de } \\
\text { connacionales } \\
(\text { a México)*** }\end{array}$ \\
\hline FY2012 & 468766 & No disponible & 372448 \\
FY2013 & 424978 & 241493 & 342667 \\
FY2014 & 350177 & 176968 & 262824 \\
FY2015 & 267885 & 146132 & 206838 \\
FY2016 & 265747 & 149821 & 216541 \\
FY2017 & No disponible & 128765 & 167064 \\
\hline
\end{tabular}

* Datos obtenidos del DHs.

** Datos obtenidos de la U.S. Immigration and Customs Enforcement (ICE).

*** Datos obtenidos de la UPM. Los datos de México se ajustaron para que coincidieran con el año fiscal estadounidense que es del $1^{\circ}$ de octubre al 30 de septiembre.

Fuente: elaboración propia con datos de la UPM, ICE y DHS.

Así, la elección de Trump ha significado un cambio no sólo en el discurso, sino en el fortalecimiento de la burocracia encargada de las deportaciones. Hasta antes del 11 de septiembre, el Servicio de Inmigración y Naturalización (INS, Immigration and Naturalization Services, por sus siglas 
en inglés) del Departamento de Justicia era responsable de la deportación de migrantes indocumentados y, ocasionalmente, efectuaba detenciones en lugares de trabajo; sin embargo, no tenía la capacidad humana para deportar a la mayoría de la población indocumentada. Después del 11 de septiembre, como parte del Departamento de Seguridad Interior, se creó la agencia ICE (Immigration and Customs Enforcement, por sus siglas en inglés). Además, durante la administración de Barack Obama, el Congreso aprobó 18000 millones de dólares para atender el tema de la inmigración.

Como vimos (cuadro 2), en 2013 la administración de Obama deportó a más de 438000 inmigrantes indocumentados. Varios analistas consideran que el objetivo era demostrar a los republicanos su interés en una reforma migratoria amplia y que, a cambio, su régimen actuaría contra la inmigración indocumentada; sin embargo, al no obtener tal reforma, Obama estableció una serie de reglas sobre los procedimientos de deportación que tornarían más complicado el proceso de deportaciones. Además, en 2012 Obama presentó DACA (Deferred Action for Childhood Arrival por sus siglas en inglés) una decisión presidencial que protegía a los menores que habían entrado como indocumentados a Estados Unidos y que han permanecido en ese país durante años.

No obstante, el presidente Trump, mediante una nueva orden presidencial, desmanteló DACA creando una crisis institucional y humana para los jóvenes hijos de migrantes. Asimismo, acusó al Congreso de no lograr un acuerdo sobre la ley migratoria y presentó su orden ejecutiva como una forma de forzarlo a actuar, aunque eso no ocurrió.

Un antecedente de la política actual fue la operación "espalda mojada", que bajo la administración del presidente Eisenhower fue responsable de la deportación de más de un millón de indocumentados. Es verdad que en este momento, ICE (Oficina de Inmigración y Control de Aduanas) no tiene la capacidad para deportar a los 11 millones de personas indocumentadas, sin embargo, las leyes vigentes le dan la autoridad técnica para hacerlo. En los primeros meses de 
la administración Trump, ICE aumentó el número de arrestos de inmigrantes en $42 \%$. Asimismo, las cortes encargadas de los casos de inmigrantes indocumentados están rebasadas, con más de 700000 casos pendientes de juicio, lo que hasta cierto punto evita un éxodo más amplio.

De acuerdo con el Pew Research Center, en 2016 había 1300000 indocumentados mexicanos menos que en 2007; incluso con el aumento de centroamericanos (hondureños, salvadoreños y guatemaltecos) que cruzan la frontera, el número de indocumentados ha disminuido. Mientras que en 2000, 1.7 millones de personas fueron detenidas al trasponer la línea divisoria entre ambos países, en 2016 fueron 300000 personas. Contrario a lo que afirma el presidente Trump, hoy la frontera entre México y Estados Unidos está más vigilada y controlada que nunca.

En medio de esta situación, el 12 de octubre de 2018, una serie de organizaciones lanzaron una convocatoria a través de Facebook y Twitter para iniciar una caravana migrante en San Pedro Sula, Honduras, hacia Estados Unidos. La crisis económica, la creciente inseguridad y la pobreza llevaron a miles de hondureños a decidir integrarse a ésta. Según algunos cálculos, 1200 personas formaron la primera expedición. El presidente Trump no perdió la oportunidad de enviar un tuit el 16 de octubre en el que amenazaba con detener el financiamiento humanitario de Estados Unidos a Honduras, El Salvador y Guatemala, pero más que desalentarlos, parece que se acrecentó el interés por ser parte del éxodo y para el 17 de octubre, cuando la caravana llegó a la frontera de México con Guatemala, ya eran más de 3000 personas.

El gobierno mexicano pidió la intervención del Alto Comisionado de Naciones Unidas para los Refugiados (ACNUR) para gestionar las solicitudes de asilo de los migrantes provenientes de Honduras, El Salvador y Guatemala. Por su parte, durante las campañas electorales de 2018, Trump retomó el tema de la inmigración y afirmó que utilizaría al ejército para proteger la frontera, incluso se tomaron videos de campaña 
en contra de esta situación que mostraban el caso de un indocumentado mexicano que había cometido un crimen. Trump consideró que el tema le permitiría movilizar a sus bases para evitar una derrota en las elecciones intermedias.

El 20 de octubre ingresaron a México más de 4500 personas y el 27 de octubre el presidente Peña Nieto anunció el programa "Estás en tu casa", para facilitar servicios de salud y trabajo temporal a quienes solicitaran refugio en el país. Nuevas caravanas migrantes salieron de Honduras y el Salvador, y el 29 de octubre Trump anunció el despliegue de 5200 soldados en la frontera con nuestro país. El $1^{\circ}$ de noviembre declaró que se movilizarían más militares y que si se les atacaba con piedras, éstos dispararían contra los migrantes.

El 6 de noviembre se celebraron las elecciones intermedias en Estados Unidos y el Partido Demócrata logró el control de la mayoría de la Cámara de Representantes, sin embargo, en el Senado se mantuvo la mayoría republicana. La estrategia de Trump de valerse del tema de la migración para movilizar a sus bases parece que funcionó en los distritos rurales, no así entre la población de las ciudades ni en los suburbios, en donde parte del electorado lo abandonó y, por el contrario, aceptó el argumento de los candidatos demócratas de proteger el sistema de salud establecido por la administración de Obama. El 9 de noviembre, el presidente Trump firmó una nueva orden ejecutiva para impedir que los migrantes que cruzaran la frontera con México de manera irregular pudieran solicitar asilo.

Históricamente, los flujos migratorios responden a realidades económicas y sociales complejas que los gobiernos de Estados Unidos y México han tratado de administrar de diversas formas. Dadas las dinámicas demográficas, está claro que la migración de mexicanos hacia Estados Unidos va disminuyendo y hoy son más los mexicanos que regresan a México que los que salen; en cambio, la migración de guatemaltecos, hondureños y salvadoreños no parece disminuir, con lo cual es probable que la presión sobre México crezca en los próximos años. 
En diversos momentos se han planteado acciones de cooperación multilateral que atiendan los problemas socioeconómicos generados por los flujos migratorios, pero éstas no se han puesto en marcha y la dinámica de conflicto que se ha generado entre Estados Unidos y los países centroamericanos, incluido México, no permite vislumbrar una política para enfrentar la situación en el corto plazo. El nuevo representante del poder ejecutivo mexicano, encabezado por Andrés Manuel López Obrador, ha hablado de programas de asistencia y cooperación económica, pero los recursos son muy limitados y el actor con más recursos (Estados Unidos) no parece estar interesado ni tener la capacidad para ver más allá del muy corto plazo.

Analicemos ahora un área en el que la cooperación, e incluso la integración, entre México y Estados Unidos parece avanzar: el comercio.

\section{El COMERCIO}

La dependencia de México del mercado estadounidense es significativa. Por una parte, las exportaciones mexicanas que se concentraron de manera creciente en EEUU, en 2012 eran de $77.7 \%$ y actualmente son casi de $80 \%$; las importaciones, por su parte, también provienen de Estados Unidos en más de $80 \%$. Esta situación se ha acentuado en las últimas dos décadas, como consecuencia del modelo de desarrollo seguido por México desde mediados de los años ochenta.

Como sostiene Luz María de la Mora en este mismo número de Foro Internacional: "México mantuvo su dependencia del exterior como uno de sus principales motores del crecimiento. De hecho, el índice de apertura comercial (contribución del comercio total de bienes y servicios al PIB) se incrementó en el sexenio llegando a $77 \%$ en 2017 , lo que demuestra la importancia del comercio exterior para la economía mexicana y su creciente integración a la economía internacional". Aunque más que a la economía internacional, la integración ha sido a la economía estadounidense. 
GRÁFICA 2

Importaciones/Exportaciones con Estados Unidos 2012-2016, millones de dólares

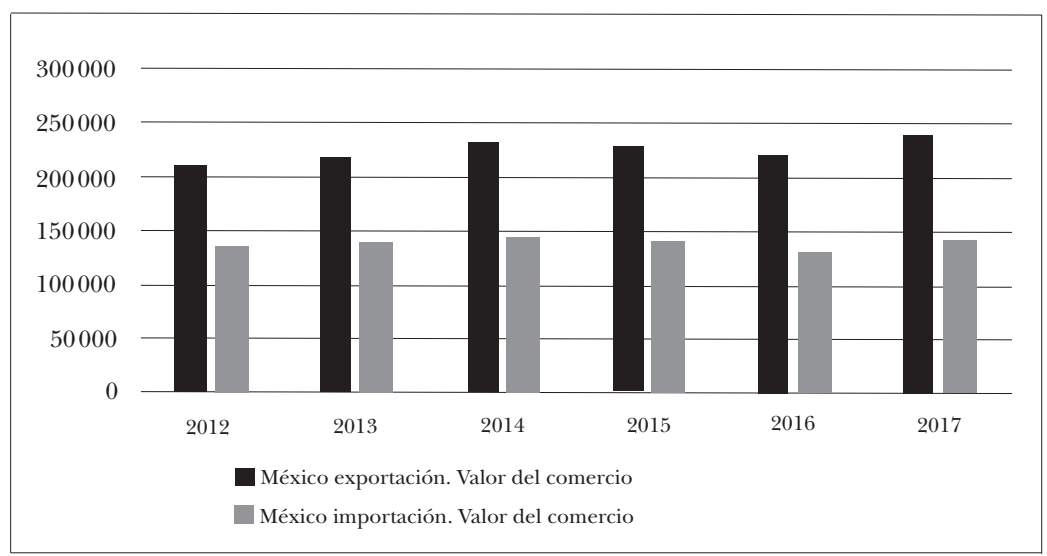

Fuente: Secretaría de Economía, Subsecretaría de Comercio Exterior, "Importaciones totales de México", https://www.gob.mx/cms/uploads/ attachment/file/412348/Acum-Importa-sep2018.pdf y https:/ /www.gob. $\mathrm{mx} / \mathrm{cms}$ /uploads/attachment/file/412347/Acum-Exporta-sep2018.pdf

Ante esta situación, la vulnerabilidad de México en la adopción de decisiones del presidente de Estados Unidos no podría ser mayor. Desde su campaña presidencial, Trump insistió en que el TLCAN era injusto para su país y que era necesario cancelarlo o renegociarlo. ${ }^{16}$ En diversos actos durante la campaña presidencial, sostuvo que las administraciones anteriores habían abandonado a los trabajadores y agricultores y que, por el contrario, él iba a anteponer los intereses de Estados Unidos a los de sus aliados.

Una vez en el poder, Trump insistió que plantearía la retirada de EeuU del TLCAN. Sin embargo, diversos actores esta-

16 Patrick Gillespie, “¿Qué es el TLCAN y por qué Trump lo odia?”, en CNN,15 denoviembre de 2016, https://cnnespanol.cnn.com/2016/11/15/ que-es-el-tlcan-y-por-que-trump-lo-odia/ 
tales y del sector privado presentaron una serie de reservas a la opinión del presidente. Por ejemplo, los militares argumentaron la importancia del TLCAN para mantener la cooperación de México y Canadá en áreas como la seguridad hemisférica, el combate al terrorismo y la lucha contra el narcotráfico. Aunado a lo anterior, incluso dentro de la administración de Trump, el secretario de Agricultura, Sonny Perdue, insistió en los beneficios del TLCAN para este sector, ya que las exportaciones agrícolas a México y Canadá crecieron en $450 \% .{ }^{17}$

Sin embargo, en abril de 2017, Trump sostuvo que firmaría una orden ejecutiva para retirarse del TLCAN. Frente a esta situación, el gobierno de México y el de Canadá tuvieron que aceptar la renegociación del tratado. Las reuniones duraron más de un año y se realizaron en forma paralela a medidas represivas de Estados Unidos contra sus vecinos.

Desde una posición de fuerza, Trump planteó una serie de demandas a sus socios comerciales -hubo quien las denominó "píldoras venenosas"-, entre las que estaban reducir la duración del tratado a cinco años, eliminar los mecanismos de solución de controversias y elevar el contenido regional del sector automotriz para favorecer la producción de autos en Estados Unidos.

Las negociaciones se iniciaron en agosto de 2017, desde posiciones muy distantes. Básicamente, la estrategia de los gobiernos de México y Canadá fue de contención de las demandas estadounidenses, para conservar el acuerdo vigente. México siguió un camino similar al de otras negociaciones comerciales al mantener un diálogo permanente con el sector privado y tratar de activar los vínculos con los grupos y gobernantes estadounidenses más afines al acuerdo; propuso una serie de rondas para tratar temas en los que no había demasiadas controversias, como propiedad

17 Nathan White, "Rural America hopes Trump hasn't forgotten his promise," The Hill, 20 de marzo de 2018. 
intelectual, comercio electrónico, telecomunicaciones, PYMES, entre otros. ${ }^{18}$

La primera ronda de negociaciones entre Estados Unidos, México y Canadá no avanzó y el 22 de agosto Trump amenazó con abandonar el acuerdo. Entre el $1^{\circ}$ y el 5 de septiembre se organizó una segunda ronda. La sorpresa vino el 14 de septiembre, cuando EeUU propuso una cláusula para revisar el tratado cada 5 años. ${ }^{19}$ En octubre de 2017, el primer ministro de Canadá, Justin Trudeau, viajó con sus socios comerciales para tratar de destrabar la negociación. ${ }^{20}$ Ésta continuó, pero en marzo de 2018, Estados Unidos impuso aranceles al aluminio y al acero, mientras México y Canadá estaban exentos temporalmente del arancel, pero con la condición de llegar a un acuerdo en mayo; como eso no se logró, el 31 de mayo Estados Unidos gravó con aranceles el aluminio y el acero de México. El 5 de junio nuestro país aplicó diversos aranceles a productos del país vecino (incluyendo impuestos de 5 a $25 \%$ a artículos derivados del acero, 20 a $25 \%$ a los quesos, $20 \%$ a papas y manzanas y $20 \%$ a la carne de cerdo), con lo cual se intentaba influir en las regiones que apoyan al presidente Trump y, el 7 de junio, México denunció a EeuU ante la Organización Mundial de Comercio (OMC). ${ }^{21}$

18 Verónica García de León, "El arte de negociar con Trump”, Revista Expansión, 15 de septiembre, de 2018, https://expansion.mx/empre sas /2018/10/02/la-estrategia-del-sector-privado-en-la-negociacion-con -eu-y-canada

${ }^{19}$ Roberto Morales, “Trump propone ratificar TLCAN cada cinco años", El Economista, 14 de septiembre de 2018, https://www.eleconomista.com. $\mathrm{mx} /$ empresas/Trump-propone-ratificar-TLCAN-cada-cinco-anos-2017 0915-0035.html

${ }^{20}$ Katie Dangerfield, "Justin Trudeau heads to Mexico after Trump says it's 'possible' NAFTA agreement won't be met”, Global News, 17 de octubre de 2017, https://globalnews.ca/news/3798727/nafta-justin-trude au-mexico/

${ }^{21}$ Ana Swanson y Jim Tankersley. "México responde a EeUu con nuevos aranceles", en The New York Times, 5 de junio de 2018, https://www. nytimes.com/es/2018/06/05/mexico-aranceles-trump/ 
Las elecciones presidenciales en México resultaron en el triunfo de Andrés Manuel López Obrador (AMLO), quien nombraría a Jesús Seade como su representante para las negociaciones sobre el Tratado. En una carta dirigida a Trump y entregada por el secretario de Estado, Mike Pompeo, el presidente electo mexicano planteó su interés en que las negociaciones comerciales tuvieran éxito y que continuaran las relaciones de cooperación entre ambos países. El 15 de agosto, el canciller Luis Videgaray, el secretario de Economía, Ildefonso Guajardo, y Jesús Seade viajaron a Washington para intentar concluir el acuerdo con Estados Unidos. ${ }^{22}$ Finalmente, el 27 de agosto Trump anunció un preacuerdo bilateral entre los dos países.

$\mathrm{Al}$ analizar los términos del nuevo acuerdo, usmC (Estados Unidos, México y Canadá, por sus siglas en inglés) queda claro que, si bien México y Canadá lograron mantener el acuerdo comercial con Estados Unidos y con ello el acceso a ese mercado, Trump impuso sus condiciones; para empezar, deja de ser permanente y se plantea que tendrá una duración de 16 años, con revisiones periódicas cada seis. Además, en la industria automotriz se establecen cambios en las reglas para considerar un automóvil como "norteamericano" y exento de impuestos. Se establece que el requisito de contenido de valor regional para autos aumente a $75 \%$ desde el $62.5 \%$ actual, en un periodo de cinco años. Para evitar aranceles, el nuevo texto requiere que el $40 \%$ del valor de los vehículos sea producido en zonas de salarios elevados, que pagan 16 dólares la hora, lo que pone a México en desventaja. El pacto también exige que los fabricantes de vehículos

22 "A un año del inicio de las negociaciones del TLCAN", El Sol de Puebla, 16 agosto de 2018, https://www.elsoldepuebla.com.mx/finan zas / tlcan-a-un-ano-del-inicio-de-las-negociaciones-mexico-eu-canada-19 20788.html y Documentos sobre la modernización del TLCAN, en Canadá-Estados Unidos- México (TLCAN/NAFTA), Sistema de Información sobre Comerció Exterior, SICE, OEA, http:/ / www.sice.oas.org/TPD/NAFTA/ NAFTA_s.ASP 
obtengan al menos $70 \%$ de su acero y aluminio de los tres países. ${ }^{23}$

En una carta paralela al acuerdo, se muestra que Trump conservó la capacidad de imponer aranceles mundiales de $25 \%$ a los autos, pero excluye los vehículos de pasajeros, camionetas y autopartes de Canadá y México. Si se imponen tarifas bajo la "sección 232" por motivos de seguridad nacional, México y Canadá obtendrían cada año una cuota de vehículos de pasajeros libres de aranceles de 2.6 millones de vehículos exportados a EeuU, lo cual está por encima de los niveles actuales de exportación. Además, México obtendrá una cuota de autopartes de 108000 millones de dólares anuales y Canadá una de 32400 millones de dólares. ${ }^{24}$

Por otra parte, se mantienen los mecanismos de solución de controversias y se evitan nuevas barreras a las importaciones de productos agrícolas mexicanos. En su estrategia de negociación, México continuó con la del Acuerdo Transpacífico y logró también concluir la modernización del acuerdo comercial con la Unión Europea. Si bien el escenario en la relación comercial no fue óptimo para nuestro país, podríamos decir que fue un escenario tipo 5, en el cual Estados Unidos gana y México empata.

\section{Consideraciones FinALES}

El nuevo residente de la Casa Blanca, Donald Trump, parece estar decidido a poner en tela de juicio las enormes ventajas que el régimen liberal le ha dado a Estados Unidos desde

23 Carlos Landetta, “¿Qué pasará con la industria automotriz con el nuevo TLCAN?”, El Universal, $1^{\circ}$ de octubre de 2018, https:/ / www.eluniver sal.com.mx/autopistas/que-pasara-con-la-industria-automotriz-en-el-nue vo-tlcan

24 "9 puntos para entender el acuerdo comercial entre México, Estados Unidos y Canadá”, Forbes, $1^{\circ}$ de octubre de 2018, https:/ / www.forbes. com.mx / asi-quedaron-los-detalles-del-acuerdo-comercial-entre-eu-ycanada/ 
su establecimiento, al final de la Segunda Guerra Mundial. El espíritu aislacionista no es ajeno a la política estadounidense; en el periodo de entreguerras, Estados Unidos se alejó de los asuntos internacionales. Es claro que en este momento la administración de Trump intenta minimizar los costos de su hegemonía y forzar a sus vecinos a asumir más responsabilidades.

En el área de seguridad, en particular en el tema del narcotráfico, los costos han sido altísimos para México, que hasta ahora ha seguido una política de militarización con la consecuente generación de más de 30000 muertos al año. Es evidente que esto no debería continuar y el nuevo gobierno mexicano ha planteado un cambio en la política al proponer la legalización de la marihuana en el país y, dado que su consumo es legal en varios estados de EEUU, es difícil que haya una oposición significativa en aquella nación a la nueva política mexicana. Sin embargo, las agencias encargadas del combate al narcotráfico insistirán en que es una política equivocada. Ahora bien, está claro que dada la situación de inseguridad pública en México, la legalización de la marihuana es sólo un ingrediente de una política más amplia que debe incluir la formación de un nuevo cuerpo de seguridad que eventualmente sustituya al Ejército en las funciones de seguridad pública que ha ido asumiendo.

Hasta ahora, las relaciones México-Estados Unidos en esta materia han estado enmarcadas por la Iniciativa Mérida, cuyos principios son muy generales:

1. Combatir a las organizaciones de crimen transnacional a partir de operaciones de cumplimiento de la ley y colaboración de inteligencia, con un énfasis en el lavado de dinero. 2. Institucionalizar el estado de derecho y proteger los derechos humanos a través de la reforma del sistema de salud y el entrenamiento de las policías federal y estatal con nuevo equipo. 3 . Crear una frontera México-Estados Unidos del siglo 21, mejorando el control y la seguridad en México y en las fronteras Sur de México y 4. Construir comunidades poderosas que per- 
mitan enfrentar las causas de la violencia apoyando los esfuerzos por reducir la demanda de drogas y construir una «cultura de la legalidad» a través de programas educativos. ${ }^{25}$

Sin embargo, detrás de esos principios lo que hemos tenido son: una militarización del combate al narcotráfico, un aumento imparable de los homicidios e inseguridad. Desde México la política ha significado sólo costos y ningún beneficio.

$\mathrm{Al}$ momento de concluir la redacción del presente artículo, el paso fronterizo de San Isidro había sido cerrado durante varias horas por Estados Unidos y habían llegado a Tijuana más de 7000 migrantes. El futuro canciller, Marcelo Ebrard, y la futura secretaria de Gobernación, Olga Sánchez Cordero, sostienen conversaciones con la administración de Trump para tratar de enfrentar la situación. Según la prensa estadounidense, se está planteando que los centroamericanos permanezcan en México mientras tramitan sus solicitudes de asilo a Estados Unidos. Hasta ahora quienes entraban a los Estados Unidos eran llevados a centros de detención mientras tenían una audiencia, primero con un agente migratorio $\mathrm{y}$ al final con un juez estadounidense que decidía el caso.

Hasta ayer, el futuro canciller ha dicho que México no aceptaría la política de tercer Estado propuesta por EEUU, es decir, que México recibiera a los migrantes centroamericanos y permanecieran detenidos aquí en tanto no se resolvieran los casos de asilo. En promedio, los procesos de asilo en las cortes estadounidenses tienen una duración de dos años $y$, debido a que las solicitudes han aumentado, los procesos se han vuelto más largos. En septiembre, más de 16658 personas fueron aprehendidas en la frontera y en abril la política de "cero tolerancia", que consistía en considerar como criminales a todos aquellos que cruzaran la frontera en forma ilegal, llevó a la separación de casi 3000 niños de sus familias que se encontraban a la espera de sus peticiones de

25 U.S.A. Congress, Congressional Research Services, "Mexico: Evolution of the Mérida Initiative, 2007-2019”, 23 de julio de 2018. 
asilo o residencia. Ante la presión de organizaciones civiles e internacionales, así como de senadores estadounidenses, Trump tuvo que detener esa política, pero todavía hoy no se ha logrado que todos los niños se reúnan con sus padres.

Es probable que la crisis actual lleve al gobierno mexicano a aceptar que miles de centroamericanos permanezcan en México en tanto se procesan las solicitudes de asilo, sin embargo, es necesaria una visión de más largo plazo, ya que es claro que los flujos migratorios continuarán.

En el área de comercio, si bien México y Canadá contuvieron la amenaza de Trump de dar por terminado el TLCAN, el nuevo acuerdo usmc implica costos para la industria mexicana y un horizonte temporal limitado. Aunado a lo anterior, la administración Trump tiene una visión mercantilista del comercio internacional que llevará a conflictos continuos. En ese sentido, será fundamental que México fortalezca nuevos mercados, en particular en Europa y Asia, para lo cual debería modernizar su infraestructura portuaria.

En la revisión que hice de las tres áreas de política es claro que Estados Unidos ha impuesto sus políticas, con una capacidad de resistencia muy limitada por parte del Estado mexicano. Pero como afirmó en su momento el presidente francés Emmanuel Macron, la consecuencia no buscada de las presiones estadounidenses es la búsqueda de mayor autonomía por parte de los países afectados. En este caso B (México) tendrá no sólo que resistir, sino buscar alternativas. En el área de comercio, la estrategia mexicana de buscar aliados en el ámbito político estadounidense fue relativamente eficaz. Los empresarios, gobernadores y representantes de ese país con intereses en la relación México-EeuU fueron relevantes para poner límites al presidente Trump, pero es una política que tiene que institucionalizarse y no sólo activarse en las situaciones de crisis.

Hasta el momento, los gobiernos mexicanos, tanto el saliente como el entrante, han tratado de mantener los ámbitos de política separados, sin embargo, es probable que la nueva administración se vea obligada a vincular los temas. 
Como sostuvo el presidente electo, López Obrador, en su comunicación con Trump, la migración, por ejemplo, no puede explicarse sin considerar los problemas de desarrollo, y si Estados Unidos insiste, como lo está haciendo, en que México coopere en el tema migratorio, el país anglosajón también debería cooperar en programas de desarrollo más amplios que permitan enfrentar los orígenes de las migraciones. En el tema de la seguridad, el gobierno mexicano debe seguir insistiendo en la necesidad de que Estados Unidos controle el tráfico de armas hacia nuestro territorio y es momento de que las autoridades mexicanas establezcan programas de control y revisión más estrictos, que impidan el trasiego de armas hacia México.

Ahora bien, si al final no existe voluntad del gobierno de Estados Unidos, el de México tendrá que dejar de aceptar las condiciones impuestas y tratar de establecer la relación bajo nuevos términos. Con el triunfo de los demócratas en la Cámara de Representantes, Trump está en una posición defensiva, pero se vislumbra una administración más agresiva que buscará fuera de Estados Unidos los orígenes a problemas internos que el presidente en turno no es capaz de enfrentar. A las agresiones habrá que responder con cierta indiferencia y propuestas de política claras.

\section{Bibliografía}

"9 puntos para entender el acuerdo comercial entre México, Estados Unidos y Canadá”, Forbes, $1^{\circ}$ octubre de 2018, https:// www.forbes.com.mx/asi-quedaron-los-detalles-del-acuerdocomercial-entre-eu-y-canada/

"A un año del inicio de las negociaciones del tLCAN", El Sol de Puebla, 16 de agosto de 2018, https://www.elsoldepuebla.com. $\mathrm{mx} /$ finanzas/tlcan-a-un-ano-del-inicio-de-las-negociacionesmexico-eu-canada-1920788.html

"Mexico: Evolution of the Mérida Initiative, 2007-2019", U.S.A Congress, Congressional Research Services, 23 julio de 2018. 
"National Drug Threat Assessment", National Drug Intelligence Center, U.S. Department of Justice, 2009, http:/ / www.justice. gov/archive/ndic/pubs

Baldwin, David A., Power and International Relations. A conceptual Approach, Princeton, University Press, 2016.

DAHL, Robert, "The Concept of Power", Behavioral Science, 2 (julio de 1957), pp. 201-215.

Dangerfield, Katie, "Justin Trudeau heads to Mexico after Trump says it's 'possible' NAFTA agreement won't be met", Global News, 17 de octubre de 2017, https:/ / globalnews.ca/news/379 8727/ nafta-justin-trudeau-mexico/

Federal Elections Commission, Election Results for the U.S. President, the U.S. Senate and the U.S. House of Representatives, Washington D.C. Federal Elections Commission, diciembre de 2017 , p. 5.

García de León, Verónica, "El arte de negociar con Trump", Expansión, 15 de septiembre de 2018, https://expansion.mx/ empresas/2018/10/02/la-estrategia-del-sector-privado-en-lanegociacion-con-eu-y-canada

GiLlesPie, Patrick, “¿Qué es el TlGan y por qué Trump lo odia?”, en CNN, 15 de noviembre de 2016, https://cnnespanol.cnn. com/2016/11/15/que-es-el-tlcan-y-por-que-trump-lo-odia/

Grace, Carrie, "Por qué la decisión de Trump de retirar a eeuu del Acuerdo Transpacífico (TPP) es una gran noticia para China”, BBC News, 23 de enero de 2017, https://www.bbc.com/ mundo/noticias-internacional-38063522

Katz, Friedrich, La guerra secreta en México: Europa, Estados Unidos y la Revolución Mexicana, México, Era, 1982.

Landetta, Carlos, “¿Qué pasará con la industria automotriz con el nuevo TLCAN?”, El Universal, $1^{\circ}$ de octubre de 2018, https:/ / www.eluniversal.com.mx/autopistas/que-pasara-con-la-indus tria-automotriz-en-el-nuevo-tlcan

Meyer, Lorenzo, Su majestad británica contra la Revolución mexicana, 1900-1950: el fin de un imperio informal, México, El Colegio de México, 1991. 
Meyer, Lorenzo, "The United States and Mexico, The Historical Structure of Their Conflict", Journal Of International Affairs, vol. 43, núm. 2 (invierno de 1990), pp. 251-271.

Morales, Roberto, "Trump propone ratificar TLCAN cada cinco años", El Economista, 14 de septiembre de 2018, https://www. eleconomista.com.mx/empresas/Trump-propone-ratificarTLCAN-cada-cinco-anos-20170915-0035.html

OJeda, Mario, Alcances y límites de la política exterior de México, México, El Colegio de México, 1976, p. 93.

Salazar Viniegra, Leopoldo, "El Mito de la Marijuana", Criminalia, México, diciembre de 1938, pp. 206-37.

Swanson, Ana y Jim Tankersley, "México responde a eeuu con nuevos aranceles", The New York Times, 5 de junio de 2018, https:/ /www.nytimes.com/es/2018/06/05/mexico-arancelestrump/

Trump, Donald, “Tuit” del 15 de junio 2015, citado por Katie Railly, Time, 31 de agosto del 2016.

UlloA, Berta, La revolución intervenida: relaciones diplomáticas entre México y Estados Unidos (1910-1914), México, El Colegio de México, 1971.

WAgner, Harrison R., War and the State: The Theory of International Politics, Ann Arbor, MI, University of Michigan Press, 2007, p. 12.

Walker, William, Drug Control in the Americas, Albuquerque, University of New Mexico Press, 1981, pp. 124-125.

White, Nathan, "Rural America hopes Trump hasn't forgotten his promise", The Hill, 20 de marzo de 2018. 